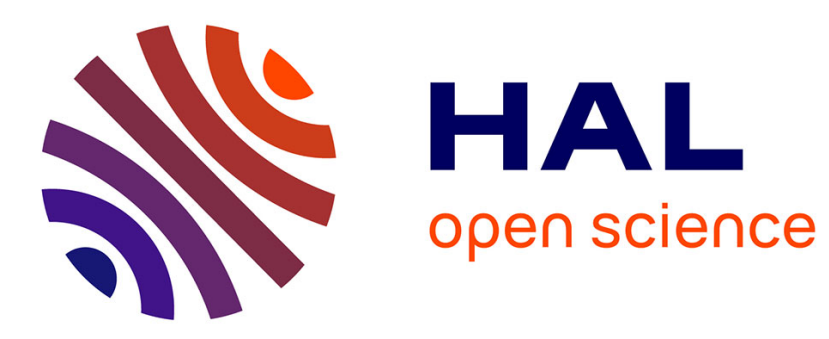

\title{
Transition from ductile to brittle failure of sodium silicate glasses: a numerical study
}

Gergely Molnar, Patrick Ganster, Anne Tanguy, János Török, Guillaume

Kermouche

\section{- To cite this version:}

Gergely Molnar, Patrick Ganster, Anne Tanguy, János Török, Guillaume Kermouche. Transition from ductile to brittle failure of sodium silicate glasses: a numerical study. MRS Advances, 2016, 1 (24), pp.1797-1802. 10.1557/adv.2016.166 . hal-02132519

\section{HAL Id: hal-02132519 https://hal.science/hal-02132519}

Submitted on 14 Apr 2020

HAL is a multi-disciplinary open access archive for the deposit and dissemination of scientific research documents, whether they are published or not. The documents may come from teaching and research institutions in France or abroad, or from public or private research centers.
L'archive ouverte pluridisciplinaire HAL, est destinée au dépôt et à la diffusion de documents scientifiques de niveau recherche, publiés ou non, émanant des établissements d'enseignement et de recherche français ou étrangers, des laboratoires publics ou privés. 


\section{MIRS Advances}

\section{Transition from ductile to brittle failure of sodium silicate glasses: a numerical study}

\begin{tabular}{|r|l|}
\hline Journal: & 2015 MRS Fall Meeting \\
\hline Manuscript ID & MRSF15-2309637.R1 \\
\hline Manuscript Type: & Symposium ZZ \\
\hline Date Submitted by the Author: & n/a \\
\hline Complete List of Authors: & $\begin{array}{l}\text { Molnar, Gergely; MINES Saint-Étienne } \\
\text { Ganster, Patric; MINES Saint-Étienne } \\
\text { Tanguy, Anne; INSA Lyon } \\
\text { Török, János; Budapest University of Technology and Economics } \\
\text { Kermouche, Guillaume; MINES Saint-Étienne }\end{array}$ \\
\hline Keywords: & amorphous, microstructure, ductility \\
\hline \multicolumn{2}{|l}{} \\
\hline
\end{tabular}




\title{
Transition from ductile to brittle failure of sodium silicate glasses: a numerical study
}

\author{
Gergely Molnár ${ }^{1}$, Patrick Ganster ${ }^{1}$, Anne Tanguy $^{2}$, János Török $^{3}$, Guillaume Kermouche ${ }^{1}$ \\ ${ }^{1}$ École de Mines de Saint-Étienne, Centre SMS, Laboratoire Georges Friedel, CNRS-UMR5307, \\ 158 Cours Fauriel, 42023, Saint- Étienne, France. \\ ${ }^{2}$ Laboratoire de Mécanique des Contacts et des Structures, Institut National des Sciences \\ Appliquées de Lyon 18-20, rue des Sciences, 69621, Villeurbanne Cedex, France. \\ ${ }^{3}$ Department of Theoretical Physics, Budapest University of Technology and Economics, \\ Budapest H-1111, Hungary.
}

\begin{abstract}
Using molecular statics calculations, sodium silicate glasses are expanded in an isotropic manner to analyze the composition dependence of the mechanical response.

Increasing the amount of sodium makes the systems more ductile. The tensile strength is reduced and the final load bearing strain limit is increased.

Hydrostatic strain hardening appears in the ductile samples. To explain this phenomena, the density is coarse-grained to identify microscopic defects. In samples containing a significant amount of sodium, a large amount of nano-voids appear before reaching the maximum load bearing capacity. In high sodium content silicates these cracks may cause the hardening observed in the pressure results.

In samples with low sodium content, the failure is abrupt and only a large crack is observed. Increasing the amount of long term but weaker Na-O interactions, instead of the short range Si-O ones could explain the observed transition.
\end{abstract}

\section{INTRODUCTION}

Silicate glasses are widely used for their ease in forming and recycling, among other interesting physical and mechanical properties. Sodium silicates have a complex mechanical behavior resulting from the mixing of two different materials: silica as network former, and sodium oxide, where sodium acts as a network modifier. Sodium-silicate glasses are known as "normal", while pure silica glasses have an anomalous mechanical behavior characterized by their densification upon compression at small scales [1]. Understanding small-scale plastic behavior of silicate glasses is crucial to understand crack initiation processes and the brittle behavior of glasses at large scales [2]. Dynamic crack formation was widely investigated in the literature for pure silica [3-6]. Rountree et al. [5] showed that even for brittle materials, the material near the crack tip becomes ductile. A good qualitative agreement was found between their results and experimental observations.

Experiments showed [7] that the network modifier ion (e.g. sodium) has a significant effect on the ductility of the material. Sodium makes the original silica network to yield at an early stage, consequently creates a higher plastic strain resistance. To investigate this topic, atomistic simulations were performed using hydrostatic tension tests.

We use a static calculation scheme [10], which can establish the connection between time-less particle and static continuum methods. Contrary to molecular dynamics, in molecular statics time and loading rate have no effect on the simulation results. 
The paper is structured as follows: first the basic methods and techniques are presented, then the simulation results are shown. Finally a short discussion on the potential function and a conclusion ends the paper.

\section{METHOD}

To model the interatomic interactions, BKS potential [8] was used with the parameters of Yuan and Cormack [9] completed with a repulsive function [10]. Cutoff in the Buckingham potential was tuned to reproduce experimental densities. The amorphous glass samples were generated by random sequential placement of the atoms in the periodic simulation box $\left(L^{3}=\sim 100^{3} \AA^{3}\right)$. After which molecular dynamics simulations using LAMMPS software [11] were conducted to melt and equilibrate the material at $3000 \mathrm{~K}$ for $100 \mathrm{ps}$. Then the samples were quenched to $10^{-5} \mathrm{~K}$ using $10^{13} \mathrm{~K} / \mathrm{s}$ cooling rate. Following the composition: $\mathrm{Na}_{2} \mathrm{O}-(100-\mathrm{x}) \mathrm{SiO}_{2}$ glass systems with $\mathrm{x}=5,15$, and $30 \% \mathrm{~mol}$ (referred as NSx5, NSx 15 and NSx30) were generated with 67041,69849 and 73368 atoms respectively. The structural and mechanical properties of the generated samples are in good accordance with experimental data from literature [12-14] and with the results of Yuan and Cormack [9].

The systems were tested by deforming the periodic simulation box homogeneously and quasistatically [15]. The dimensions of the simulation box were increased isotropically by a constant displacement step $(d L=0.01 \AA)$, while the positions of the particles were rescaled in a homogeneous way. After the box deformation Polak-Ribiere conjugate gradient algorithm was used to search for a new equilibrium position.

To measure permanent (plastic) volume change, the direction of the deformation was reversed from several states to relax the pressure to zero. Then the relaxed and the original volume size was compared to calculate permanent volumetric strains.

Samples were considered brittle, if the load bearing capacity reduced significantly in a few steps. They were considered ductile if this transition was observed in a large strain interval.

To analyze void formation during the deformation, the density of the samples were coarse grained on a $100 \times 100 \times 100$ grid using the following Gaussian function:

$\rho(\mathbf{r})=\sum_{I} m_{i} \phi\left(\left\|\mathbf{r}-\mathbf{r}_{i}\right\|\right)$, and $\phi(r)=\frac{1}{\pi^{3 / 2} w^{3}} e^{-(r / w)^{2}}$,

where $\mathbf{r}_{i}$ is the position of atom $i$ with mass $m_{i}, \mathbf{r}$ is the position of the observed grid point and $w$ is the coarse graining scale $(w=8 \AA)$. Voids correspond to the density values under the limit of $0.1 \mathrm{~g} / \mathrm{cm}^{3}$.

\section{RESULTS}

In Fig. 1 the governing pressure results are shown as a function of volumetric strain for different compositions. It can be seen that $\mathrm{NSx} 5$ has the maximum pressure resistance and that this value reduces gradually by the increase of the sodium content.

NSx 15 is considered a transition composition between a low (NSx5) and a high (NSx30) sodium content material. 


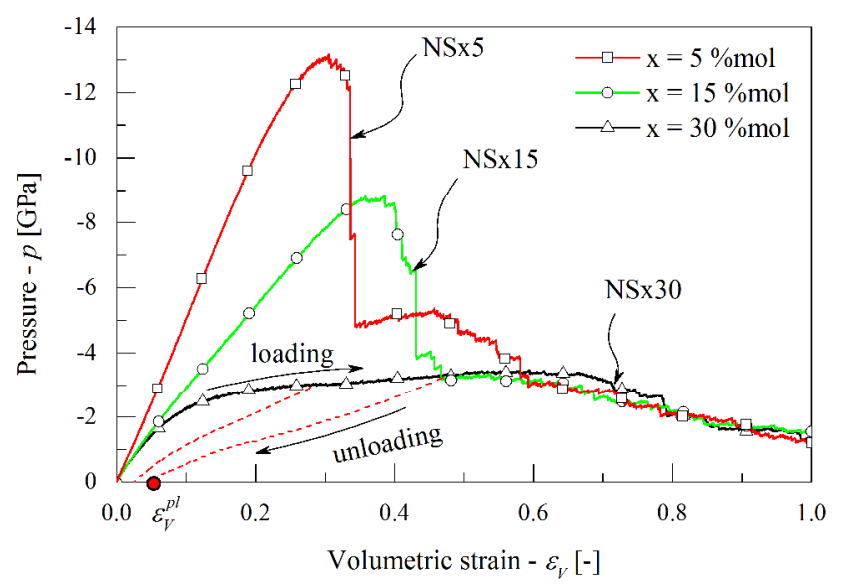

Figure 1 Pressure as a function of volumetric strain for NSx5 (squares), NSx15 (circles) and NSx30 (triangles). Red dashed lines show the unloading paths used to evaluate the permanent volume change.

The maximum load bearing capacity is reached at $0.28,0.38$ and 0.67 strain for NSx $5, \mathrm{NSx} 15$ and NSx30 respectively. This result confirms the experimental observation [7], that the microscopic response of silicates is highly affected by its composition. More specifically it shows that the addition of the network modifier tends to reduce the resistance and increase ductility. The pressure results not only show a non-linear response upon tension, but a plastic transformation.

In Fig. 1 red dashed lines show how permanent volume change is calculated. First the samples are extended until $p$ pressure (loading), then the deformation is reversed (unloading) and the samples are compressed and the pressure is relaxed to zero. The resulting volume (at zero pressure) is then compared to the original unreformed one to calculate the permanent volume variation.

Fig. 2 shows the permanent volumetric strain for different glass compositions. The permanent volume change shows that NSx30 can support larger permanent volume variation without failure.

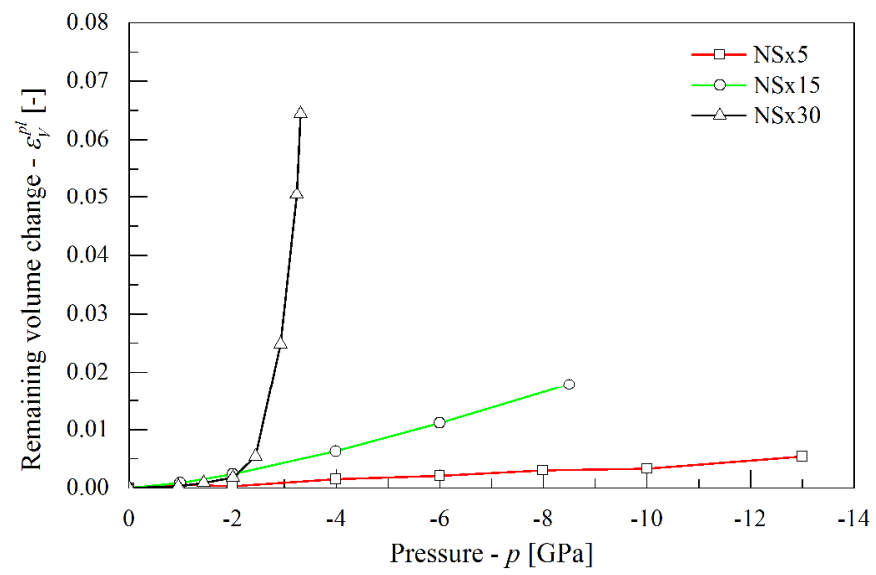

Figure 2 Permanent (plastic) volume change as a function of applied maximum pressure for different compositions. 
It can be seen, that NSx 5 is only slightly sensitive to plasticity but reaches a considerably high tensile strength, and therefore it is considered brittle. On the other hand, NSx30 has a much lower resistance and its volume increases before reaching its maximum pressure state.

The explanation of this phenomena lies in the microscopic structure. Using atomistic methods, it is very difficult to define a perfect void in the sample. Therefore, coarse-graining technique was used, and a continuum based density was calculated from the atomic positions. Fig. 3 shows the isosurface of the density value of $0.1 \mathrm{~g} / \mathrm{cm}^{3}$, which was considered as a void.
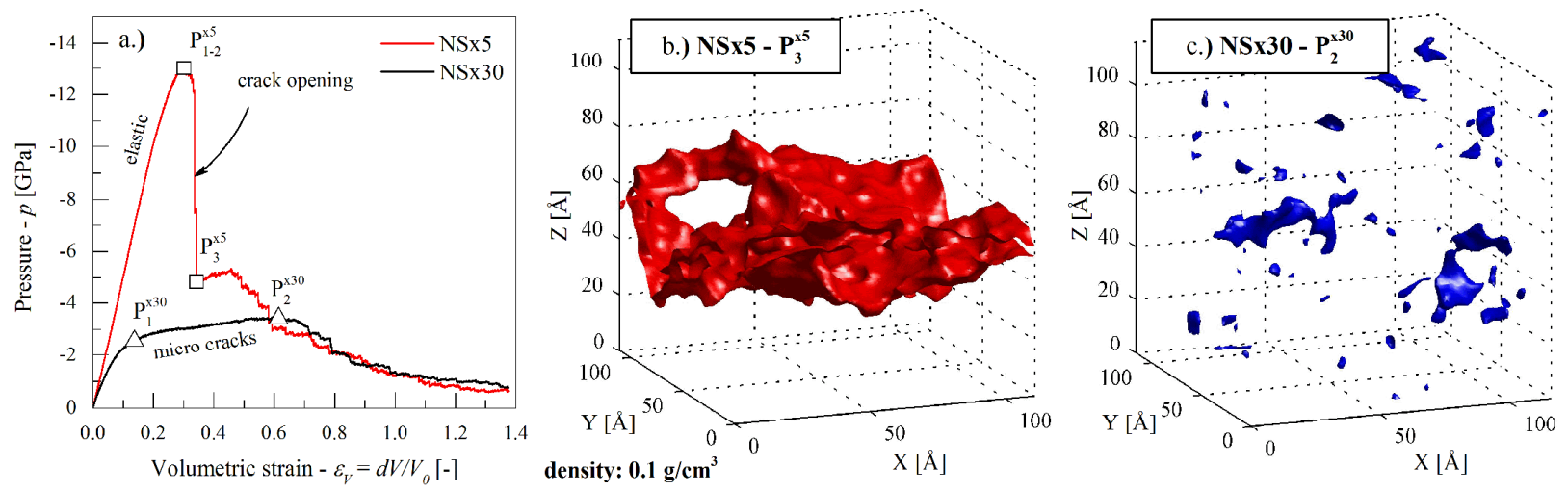

Figure 3 Crack formation upon isotropic tension for two different compositions. a.) Pressure-strain relationship for NSx5 (red) and NSx30 (black), showing each important state with symbols: $P_{1}$ - no void is observed in the material; $P_{2}$ - maximum pressure; $P_{3}-$ after a significant pressure drop. $b$.) Visualization of the crack in NSx5 samples after the stress drops $\left(P_{3}\right)$. c.) Micro cracks in NSx30 at maximum pressure $\left(P_{2}\right)$.

Fig. 3a shows important stages of the loading for Nsx 5 and Nsx30 sample: $\mathrm{P}_{1}$ is a quasi-elastic limit, when no void is present in the sample; $\mathrm{P}_{2}$ shows the maximum pressure value; $\mathrm{P}_{3}$ is the point after macroscopic failure.

For Nsx 5 sample, $\mathrm{P}_{1}$ and $\mathrm{P}_{2}$ overlap and no crack formation is observed before the first pressure drop. Before reaching $\mathrm{P}_{3}$ stage, a large pressure drop occurs in few loading steps indicating an abrupt crack manifestation (initiation and propagation). The remaining loadbearing capacity does not become zero, because $\mathrm{X}$ and $\mathrm{Y}$ directional stresses are still present and the pressure is calculated by averaging all axial components. In Fig. $3 \mathrm{~b}$ the isosurface of the crack is shown at $\mathrm{P}_{3}$. The crack separates the whole system, thus weakening the structure in an irreversible way. In NSx30 $\mathrm{P}_{1}$ and $\mathrm{P}_{2}$ stages are separated. From $\mathrm{P}_{1}$ to $\mathrm{P}_{2}$ the pressure increase corresponds to a plastic strain hardening stage. In NSx30, at the maximum pressure, several micro cracks are observed at different locations (Fig 3c). Finally, a stable crack opening regime decreases the resistance of the sample. As the pressure response of NSx30 sample does not present a significant stress drop after $\mathrm{P}_{2}$, the stage corresponding to $\mathrm{P}_{3}$ cannot be defined precicly. Globally the sample softens gradually. Note that after the large stress drops every composition shows similar load bearing capacity at the plastic plateau. 


\section{DISCUSSION}

Explanation for the previously observed phenomenon can be found in the potential function (detailed information about the form and the parameter values of the functions can be found in Ref. [8-9]). There are only two types of pairs which show attraction: Si-O and Na-O.

Fig 4 shows the contact force (first derivative of the potential) for Si-O and Na-O pairs. With triangles the maximum load bearing, with rhombus the equilibrium distance are shown. At both distances the corresponding force value is displayed. For Si-O the maximum tensile strength is at $r=1.81 \AA$ and the maximum tensile force is $-12.32 \mathrm{eV} / \AA$. Whereas, for Na-O this distance is much larger $r=2.49 \AA$ and the force is much

smaller: $-1.37 \mathrm{eV} / \AA$. Compared to $\mathrm{Na}-\mathrm{O}$, the Si-O connections are much more localized, but stronger. Therefore, according to the potential functions for Si-O dominated systems a higher elastic strength can be observed, which leads to a rapid but brittle failure. While, for high content sodium materials a larger ratio of $\mathrm{Na}-\mathrm{O}$ connections reduce the maximum strength but the systems remain more connected during the failure, which leads to a ductile response. The potential functions were developed by fitting lattice parameters for crystalline [8] and structural properties for amorphous [9] silicates. Therefore, it is interesting that the calibrations done considering structural parameters can reproduce macroscopically measured [7] change in the mechanical behavior.

However, to precisely explain this microscopic phenomena and to calculate tensile strength, it would be essential to take the elementary events (shear transformation zones [16-17]) into account, even upon hydrostatic deformation.

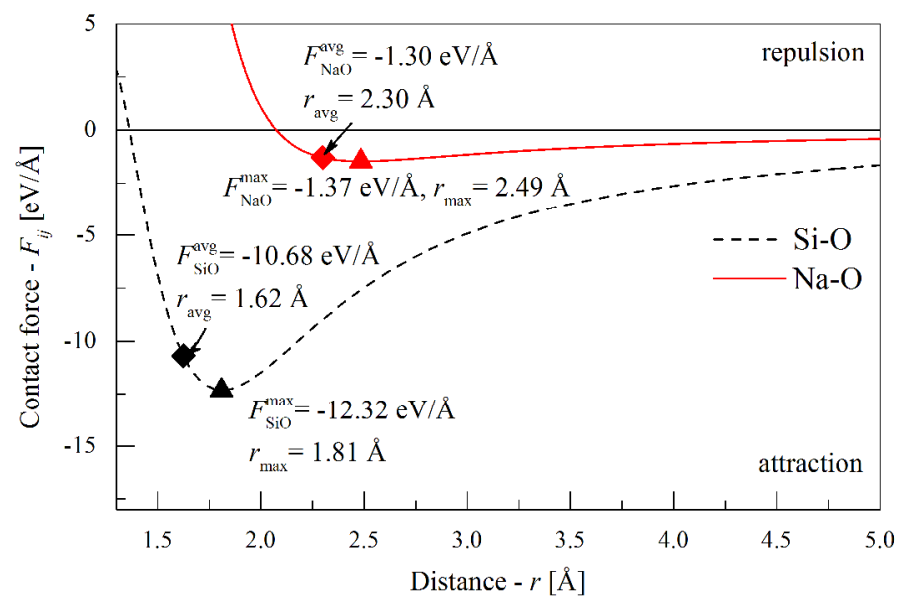

Figure 4 First derivative of the potential function respect to the interatomic distance (contact force) for Si-O and Na-O pairs. Triangle shows the maximum attraction value (local minimum), and rhombus indicates the equilibrium distance at zero pressure and $0 \mathrm{~K}$.

\section{CONCLUSION}

Sodium silicate samples were tested to explain the transition between brittle and ductile response observed in experiments [7].

The samples were deformed in an isotropic manner. First, all samples were expended, then at certain pressure states the deformation was reversed to calculate permanent volume changes. Using a coarse-graining algorithm, the micro cracks were identified from the local density field. 
A gradual decrement was observed in the tensile strength with the increment of the failure strain, by increasing the amount of the sodium in the system.

Also it was shown that samples with more sodium exceed more volumetric plasticity before reaching their strength limit. The coarse-grained density was used to explain this transition: we found microscopic voids in the final loading stage in NSx30 which was interpreted as strain hardening at the macroscopic scale. This phenomena is absent in NSx5, where a single crack appears after reaching a quasi-elastic maximum value.

\section{ACKNOWLEDGMENTS}

The authors thank B. Ruta and D. Rodney for interesting discussions, as well as E. Barthel, B. Champagnon, C. Martinet and A. Mermet for stimulating our work. This work was supported by the French Research National Agency program MultiSil (ANR-13-BS09-0012).

\section{REFERENCES}

1. R. Brückner, Journal of Non-Crystalline Solids 5, 123-175 (1970).

2. C. Hermansen, J. Matsuoka, S. Yoshida, H. Yamazaki, Y. Kato and Y. Yue, Journal of Non-Crystalline Solids 364, 40-43 (2013).

3. K Muralidharan, J. H. Simmons, P. A. Deymier and K. Runge, Journal of NonCrystalline Solids 351, 1532-1542 (2005).

4. C. L. Rountree, S. Prades, D. Bonamy, E. Bouchaud, R. Kalia and C. Guillot, Journal of Alloys and Compounds 434-435, 60-63 (2007).

5. K. Nomura, Y.-C. Chen, W. Weiqiang, R. K. Kalia, A. Nakano, P. Vashishta and L. H. Yang, J. Phys. D: Appl. Phys. 42, 214011 (2009).

6. Y.-C. Chen, K. Nomura, R. K. Kalia, A. Nakano and P. Vashishta, Physical Review Letters 103, 035501 (2009).

7. T. M. Gross and M. Tomozawa, Journal of Applied Physics 104, 063529 (2008).

8. B. W. H. van Beest, G. J. Kramer, and R. A. van Santen, Physical Review Letters 64, $1955(1990)$.

9. X. Yuan and A. N. Cormack, Journal of Non-Crystalline Solids 283, 69 (2001).

10. B. Mantisi, A. Tanguy, G. Kermouche, and E. Barthel, The European Physical Journal B, 85 (2012),

11. S. Plimpton, Journal of Computational Physics 117, 1 (1995).

12. M. Fábián, P. Jóvári, E. Sváb, G. Mészáros, T. Proen and E. Veress, Journal of Physics: Condensed Matter 824 19, 335209 (2007).

13. J. F. Emerson, P. E. Stallworth and P. J. Bray, Journal of Non-Crystalline Solids 113, 830 (1989).

14. Q. Zhao, M. Guerette, G. Scannell and L. Huang, Journal of Non-Crystalline Solids 358, 3418 (2012).

15. D. Theodorouand and U. W. Suter, Macromolecules 19, 139 (1986).

16. F. Spaepen, Acta Metallurgica 25, 407 (1977).

17. A. S. Argon, Acta Metallurgica 27, 47 (1979).

18. D. Theodorouand and U. W. Suter, Macromolecules 19, 139 (1986). 